\title{
O ENSINO DE ARTES NA EDUCAÇÃO DE JOVENS E ADULTOS
}

\author{
Luciana Chaves S. Pereira ${ }^{1}$ \\ Verenilda Nascimento Mattos ${ }^{2}$
}

\section{Resumo}

O presente artigo é resultado de uma pesquisa bibliográfica, que buscou através de uma revisão literária no campo da educação, pedagogia e ciências sociais, abordar algumas questões que têm surgido como demandas no cotidiano escolar da Educação de Jovens e Adultos. Questões essas que perpassam pelas teorias e metodologias pedagógicas incorporadas na EJA, legislações e normativas regulatórias, desafios da docência, ausência de recursos estruturais e limites do sistema educacional brasileiro. Ademais, se propõe uma discussão sobre um ensino de qualidade, que seja integral e útil para a vida social. Abordaremos, ainda, sobre como o ensino das Artes na EJA podem impactar no processo identitário e na autoestima destes estudantes e o papel do arte-educador nesse processo de construção. Considera-se a arte-educação como possibilidade de construção e partilha de modos de viver e pensar que valorizam a reflexão e a ação política e social dos sujeitos, contribuindo, assim, para a transformação e emancipação societária.

Palavras-chaves: EJA. Artes. Transformação social.

\begin{abstract}
This article is the result of a bibliographic research, which sought, through a literary review in the field of education, pedagogy and social sciences, to address some issues that have arisen as demands in the school routine of Youth and Adult Education. These issues run through pedagogical theories and methodologies incorporated in EJA, laws and regulatory regulations, teaching challenges, absence of structural resources and limits of the Brazilian educational system. In addition, a discussion on quality education is proposed, which is integral and useful for social life. We will also address how the teaching of Arts in EJA can impact the identity process, self-esteem and mental health of these students and the role of the art educator in this construction process. Art education is considered as the possibility of building ways of living and thinking that value the subjects' political and social reflection and action, thus contributing to the transformation and societal emancipation.
\end{abstract}

Keywords: EJA. Arts. Social transformation.

\section{Introdução}

Discorrer sobre o ensino de Artes na Educação de Jovens e Adultos é uma tarefa muito complexa, pois embora se reconheça sua importância e exista uma

\footnotetext{
${ }^{1}$ Mestre em Ciências da Educação pela Faculdade Interamericana de Ciências Sociais - FICS. Especialista em Educação de Jovens e Adultos (EJA) pelo Instituto Superior de Educação Afonso Claúdio. Especialista em Psicopedagogia pela Universidade Cândido Mendes. Especialista em Informática na Educação: nova perspectiva no saber pelo Instituto Pró Saber. Especialista em Educação e Controle Ambiental pelo Instituto Pró Saber. Especialista em Gênero e Diversidade na Escola pelo Instituto Pró Saber. Licenciada em Educação Artística pela Universidade Católica de Salvador (UCSAL). Docente pela Secretaria Municipal de Educação de DIÁS DÁVILA- BAHIA. Docente pela Secretaria Estadual de Educação de Salvador-BA. Email: lucianachaves107@gmail.com

2 Mestre em Ciências da Educação pela Faculdade Interamericana de Ciências Sociais - FICS. Especialista em Educação de Jovens e Adultos e Ciências Humanas pelo Instituto Superior de Educação Afonso Cláudio. Licenciatura em Filosofia pela Universidade Católica de Salvador. Docente pela Secretaria Municipal de Educação de DIÁS DÁVILA- BAHIA. Docente pela Secretaria Estadual de Educação de Salvador-BA. E-mail. verenildanascimento@outlook.com
} 
quantidade considerável de dados e informações a respeito do ensino artístico na educação básica regular brasileira e sua história, a adição da palavra EJA diminui consideravelmente o número de produções científicas encontradas nas bases e plataformas digitais e físicas.

Também é óbvia a diferença entre o ensino estipulado pelas leis regulatórias e seus idealizadores e a prática ocorrida nas escolas de todo país, seja pela desqualificação profissional dos educadores, a desassistência governamental nas escolas, as quais apresentam variadas carências de recursos, preconceitos e visões deturpadas a cerca da disciplina e/ou pelo caráter incorporado de certificações compulsórias, que resultam na tecnificação do ensino (conteudismo e resumismo) pelos seus docentes, que atém seu ensino a livros didáticos, trabalhos acadêmicos escritos e atividades visuais genéricas.

Neste trabalho, busca-se analisar as influências que constituíram o ensino das Artes na EJA e sua trajetória na história da educação brasileira, além de questionar os impactos do ensino atual nas comunidades e favelas brasileiras, que são o grande público dessa modalidade e tem na EJA a perspectiva de melhoria de vida e caminhos de emancipação.

Além disso, discutiremos sobre um ensino integral, baseado na valorização, pertença e reconhecimento da(o) estudante enquanto protagonista do processo de educação. Abordaremos, ainda, sobre como o ensino das Artes na EJA podem impactar no processo identitário, na autoestima e saúde mental destes estudantes, que enfrentam as maiores estatísticas de evasão escolar devido a seus contextos e problemas sociais, e a transformação que pode ser feita a partir de um olhar apurado da(o) educador(a).

\section{As Pedagogias que Influenciaram o Ensino de Arte na EJA e na Educação Básica Regular}

Tal como observou Marcílio Vieira (2011), o ensino das Artes no Brasil é notado a partir de relevantes interferências culturais e sociais, as quais se deram desde o comportamento do ensino artístico visando uma preparação para o trabalho a sua inserção nas Leis de Diretrizes e Bases da Educação Nacional.

Para o autor, as tendências pedagógicas, que nortearam o processo de ensino-aprendizagem em Artes, sempre estiveram em consonância com as metodologias usadas ao longo do processo de ensinar e aprender da educação 
brasileira, percebendo-se assim, a presença das Pedagogias Tradicional, Nova, Tecnicista, Libertadora e Histórico-crítica, que consideram em seus processos ensino-aprendizagem a dimensão humana, político-social e a técnica, aplicando conhecimentos para resolver questões e problemas da escola e da sala de aula.

$\mathrm{Na}$ Pedagogia Tradicional, a qual o seu "[...] caráter educativo faz o movimento de fora para dentro, cujos valores e conhecimentos são impostos à criança, do alto para baixo, e sua função educativa é o intelectualismo" (BALDAN; ARCE, 2009, p 3), no ensino de Artes predomina-se uma perspectiva de reproduzir pra prender, com atividades que vão nomear de "atividades que tinham por finalidade exercitar a vista, a mão, a inteligência, a memorização, o gosto e o senso moral" (FUSARI e FERRAZ 1999, p.30).

Na Pedagogia Nova, responsável por nomear sua antecessora de "Pedagogia Tradicional", em um tiro profundo de crítica e desmanche aos métodos educacionais creditados, o ensino de Artes é diretamente contagiado pelo ideal de liberdade de expressão e criação. Embora revolucionária e difundida por Anísio Teixeira no Brasil, seus autores são apontados por Baldan e Acre (2009, p.3) como eventuais extremos opostos do que se é criticado no tradicionalismo.

Já, na "Pedagogia Tecnicista", constituída a partir do surgimento do ensino técnico no Brasil, que objetivava a capacitação de indivíduos ao mercado de trabalho, "[...] o aluno e professor ocupam uma posição secundária, porque o elemento principal é o sistema técnico de organização da aula e do curso" (FUSARI; FERRAZ, 1999, p.32). Neste caso, as artes se caracterizam pelo ensino regado a livros didáticos e descompromissado com as linguagens artísticas, assim como apontado pelo autor supracitado. Atrelada a esta metodologia baseada em alunos em carteiras, professores técnicos e livros didáticos, um agravante: a necessidade de rápida formação de alunos equidistantes de seus tempos formativos adequados.

\section{A Trajetória do Ensino de Arte na Educação de Jovens e Adultos (EJA)}

Com as atualizações das Leis de Diretrizes e Bases da Educação Nacional, que não somente garantiram o ensino de Artes no país (LDB nำ4024/61, nํ5692/71 e no 9394/96), um ensino direcionado a jovens e adultos passou a ser regulamentado (Lei n. 9394/96), com o intuito de simbolizar a emancipação instrutiva de uma grande parcela populacional analfabeta. Apesar desta pretensão, seu propósito converteu-se no atendimento do capital e um mercado de trabalho cada 
vez mais exigente, resultando na desqualificação do arte educador - nesse instante, profissional técnico - e na insensibilização da relação ensino-aprendizado.

A 'tecnificação' da transmissão de conhecimento dentro da área artística pode ser pensada como um fenômeno inevitável, quando analisados os poucos esforços legislativos à emancipação das Artes no ambiente escolar, atribuindo-lhe uma face influenciável, achatando sua independência e menosprezando sua importância no processo construtivo humano.

Se há mudança na perspectiva de ensino em outras áreas, derivado de influências socioculturais, há alteração no ensino das Artes: $\mathrm{Na}$ melhor das hipóteses, um ensino livre e libertador, na pior delas, seu endurecimento. Neste caso, a mesma Arte, compreendida como "[...] forma de linguagem, através da qual o ser humano expressa seus sentimentos e comunica suas experiências" (VIANA, 2017, p.2) é reduzida a alguns metros quadrados e recursos.

Todavia a avaliação do agravante que a rapidez formativa advinda da mudança de caráter da Educação de Jovens e Adultos traz, alterando o perfil, centralidade e propósitos dos estudantes dentro de sala de aula e a figura do professor também é relevante. Este, aluno/discípulo, já não é mais atraído pelo sonho de escrever o próprio nome; ter em seu histórico o Ensino Fundamental ou o Ensino Médio; todavia a ansiedade e desinteresse solidificam sua face frente à transmissão de conhecimento, garantindo, na prática, estudantes cujas únicas sinas são realizar trabalhos manuais frequentemente isentos de recursos, tal como resumos e tarefas.

O professor assume uma posição conteudista e resumista, na qual o cronograma das instituições de ensino é o seu maior inimigo e as notas o único recurso à integração do aluno - influenciada pelos paradigmas disseminados de Artes enquanto passatempo ou diversão - e agrado à nova política educacional que exige o aumento constante do IDEB escolar e certificação. Por fim, o ensino das artes no Brasil, mais especificamente, na EJA é reduzida à trindade de sua falência: alguns metros quadrados, recursos e tempo.

Mas por que a 'tecnificação' de seu ensino resulta na insensibilização deste? Ou, ainda, por que a Arte necessita de espaço, recursos e tempo? "[...] O homem escravo da técnica converte-se em humanoide, mecaniza-se e escraviza-se, abandonando sua própria essencialidade [...]" (BITTAR;ALMEIDA, 2015, p.20) 
A resposta para estas duas perguntas podem e devem ser dadas de forma intrínseca. Primeiro, porque o movimento tecnicista é o responsável por inaugurar no país uma nova perspectiva de ensino, na qual nem professor nem aluno assume o protagonismo da relação ensino-aprendizagem. Poderíamos dizer que o nome "tecnicista" não é somente construído a partir do advento do ensino técnico profissionalizante, mas pela busca incansável pelo jeito mais rápido e mecânico de se fazer ensino; "[...] a técnica que pode conduzir à alienação [...]"(BITTAR; ALMEIDA, 2015, p.04); que há muito tempo deixou seu desígnio de aperfeiçoar, para cimentar as relações. Essa questão nos remete a crítica de que:

Como tudo o que entra no entendimento humano vem pelos sentidos, a primeira razão do homem é a razão sensitiva; é ela que serve de base para a razão intelectual: nossos primeiros mestres de filosofia são nossos pés, nossas mãos, nossos olhos. Substituir tudo isso por livros não é ensinar a raciocinar, é nos ensinar a nos servir da razão alheia; é nos ensinar a crer muito e nunca saber nada (ROUSSEAU, 1999, p. 141)

Segundo, porque "[...] arte pressupõe conhecimento, por produzir e reproduzir conceitos e valores humanos projetados sobre as coisas [...]" (BITTAR; ALMEIDA, 2015, p.21) e conhecimento pressupõe experimentações. Reduzir Artes à pura técnica (livros didáticos; conceitos), negando ao ser artista - ao aluno - o experimentar; o sentir é conduzi-lo à ignorância e mera reprodução das experiências de outrem. Do mesmo modo, conduzir seu ensino assombrado pelo tempo e pelas notas - certificação compulsória - é evocar a superficialidade, bem como a falta de recursos e equipamentos limitam a independência de seu ensino.

Assim sendo, temos um ensino de Artes na EJA, que teoricamente foi sonhado por Paulo Freire e estipulado segundo suas ideias de emancipação - de mesmo modo que toda a EJA - diretamente influenciado pelo movimento tecnicista e que, desde sua inauguração, não desempenha com rigor seu papel.

\section{As Artes Encurtadas à Arte Visual}

Isentos de equipamentos e recursos, tempo e espaço educacional que permitam um desenvolvimento artístico adequado, professores da matéria de arte, que ensinam jovens e adultos foram 'forçados' à adaptação e/ou limitação no ensino da matéria ao longo da história da EJA. Restritos, a saída mais viável foi de mesmo modo restringir a Arte às atividades artísticas visuais (desenhos, pinturas e etc.). 
Tomando por base o Segundo Seguimento Ensino Fundamental da EJA, através dos estudos de Lima; Lima (2015), no qual podemos pensar a respeito da importância deste gênero artístico e estas atividades, podemos perceber o desafio enfrentado por professores que desejam o ensino artístico de forma integral e versátil, aproveitando o máximo do gênero ou explorar outros gêneros da Arte.

$O$ segundo seguimento Fundamental da EJA que elabora a base comum ao se deve ser ensinado nas Artes Visuais e outras Artes, no ensino fundamental, explicita sua preocupação educacional na promoção do desenvolvimento cultural dos estudantes por meio de seus objetivos que propõem 0 trabalho com autoconfiança, levando em conta a exclusão e baixa autoestima dos alunos desta modalidade:

\begin{abstract}
Deve-se também desenvolver o respeito pelo outro e pela diversidade artística, a expressão, representação de ideias, emoções, sensações, percepções, imaginação, memória, sensibilidade e reflexão de maneira interativa entre os sujeitos da EJA, promovendo o fortalecimento grupal e a promoção da individualidade como parte de um todo (LIMA; LIMA, 2015, p.5)
\end{abstract}

Para as Artes Visuais, especificamente, são demarcadas as proposições de conhecimento e contato constante pelo aluno de/com museus, galerias, ateliês, centros de cultura, oficinas populares e dentre outros, desenvolvendo, assim, a consciência de preservação, conservação e restauração desses locais.

Porém considerando a personalidade adaptativa da EJA, a qual em seu regulamento (Seção V, Art. 37 da Lei 9.394/1996), possui a obrigatoriedade de asseguração de oportunidades educacionais apropriadas, que atendam as características, interesses e condição de vida e de trabalho dos alunos, é possível compreender que, em suma, seu ensino ocorre à noite, visto que a carga horária mais recorrente no país é diurna; de 8 horas de trabalho.

Neste período do dia, a maior parte dos estabelecimentos de cunho artístico visual permanece sem funcionamento. Portanto, sua instrução, corriqueiramente, é atida ao estudo de conceitos ou apreciação em livros didáticos; no mais positivo dos casos, pinturas e desenhos são trabalhados, desobedecendo a recomendações do MEC, para um ensino adequado. $E$ os professores que decidem escapar deste método, incorporando outras áreas do conhecimento artístico? Pode-se afirmar que:

O professor será capaz de ensinar música a seus alunos, caso não possua uma formação completa e aprofundada em música, sabemos que, infelizmente, na escola brasileira, nem sempre o professor que ministra as aulas de música tem formação especifica. Muitas vezes ele não conhece 
nem mesmo a música como área de conhecimento, e mesmo ainda as metodologias de ensino especifico (CAMPOS; TEIXEIRA; GOELZER, [s.d]).

Certamente, estes terão que enfrentar a fadiga - derivada das condições de trabalho -, o tempo e/ou a carência formativa. Isto, porque no país "[...] a formação de professores de arte é atípico, diferente de outras licenciaturas, ela só foi considerada uma disciplina no currículo com a designação na última LDB, em 1996" (CAMPOS; TEIXEIRA; GOELZER).

Enquanto teóricos como Lanier (apud RITHER, 2005), defendem a existência de dois professores em sala de aula, no qual um centraliza-se nos conceitos e outro 'no fazer das artes', de modo com que a relação ensino-aprendizagem seja construída o mais estável e completa possível, ensino das Artes no ensino regular e EJA brasileira é elaborado a partir de arte-educadores, os quais concentram seus conhecimentos na Arte objeto de suas licenciaturas - a despeito da Arte Visual -, estando, frequentemente, inaptos ao exercício de outros tipos de atuações artísticas.

De mesmo modo, a 'tecnificação' do ensino, tratada acima, contribuiu a este cenário ao causar a desobrigação formativa em licenciatura, por parte de professores, no ensino médio e médio-técnico (adição do inciso IV no Art. 61 da LDB).

\section{A Desassistência do Ensino de Artes na EJA e a Consequente Violação de Dignidades em Comunidades Pobres e Negras Brasileiras}

A arte educação é, essencialmente, uma das mais poderosas ferramentas que podem ser usadas no desenvolvimento humano, apesar de que "[...] o adulto não volta para a escola para aprender o que se deveria ter aprendido quando criança", posto que:

Para além do legítimo desejo de reconhecimento social, ele busca a escola para aprender conhecimentos importantes no momento atual de sua vida, que the permitam desenvolver e constituir conhecimentos, habilidades, competências e valores que transcendam os espaços formais da escolaridade e conduzam à realização de si e ao reconhecimento do outro como sujeito (SÃO PAULO 2010, p.2).

Todavia os motivos que levam os estudantes de volta à escola não definem o que pode-se ser trabalho no ambiente escolar. Para Oliveira (2016), o teatro é uma linguagem dentro das Artes que lida diretamente com a expressão de diversas 
formas e é uma das poucas disciplinas que proporciona ao estudante o "levantar da cadeira" e "aprender com o corpo todo".

Ainda, através do teatro, 0 trabalho com as identidades pode ser compreendido como uma das propostas de Paulo Freire ao ensino emancipatório, ao empreender exercícios, técnicas e jogos cênicos, bem como leituras e estudos, que estimulam o autoconhecimento e a auto-aproximação. Conhecer a si mesmo, de acordo com Oliveira, é um ato de emancipação, pois torna o indivíduo mais forte. Ou seja, desperta a uma nova perspectiva sobre si mesmo, a partir de referências verdadeiras de sua história, a qual pode ser representada a partir de personagens.

Uma atividade deste gênero, nos espaços da EJA, que propunha o autoconhecimento, a partir dos estudos da história da comunidade, por exemplo, é também instigar um novo objeto na frequência das aulas, pelos discípulos, visto que estes também estarão reunidos à visualização e 'perseguição' da emancipação coletiva, compartilhando e fortalecendo uns aos outro por meio de uma convivência mais próxima e respeitosa, garantido pela competência de construção dos laços e trocas do Teatro.

Desta maneira, falar em Educação de Jovens e Adultos sem abordar sobre identidade e ou o seu trabalho através da arte educação é omitir sua influência na autoestima humana, consequente violação da dignidade das comunidades negras e pobres brasileiras, uma vez que esta modalidade de ensino é ofertada pelas escolas públicas, as quais em sua maioria atendem estudantes oriundos dessas comunidades e as comunidades propriamente ditas.

Estas são alvos de violências e desassistência das políticas públicas/governamentais responsáveis por abrigar a maior parcela de evasões do ensino básico brasileiro. Sendo assim, quando se há um trabalho que vise o estímulo do aumento do auto afeto dentro dos espaços da EJA não é somente sobre se fazer jus à visão de emancipação, defendida por Paulo Freire, como obediência à legislação brasileira, ao prever o que se é digno ao cidadão.

Neste caso, também é necessário se pensar na resignificação da palavra dignidade, quando nos referimos às comunidades. A música "Comida", da banda Titãs discorre um pouco sobre isso:

Bebida é água

Comida é pasto

Você tem sede de quê?

Você tem fome de quê? 
A gente não quer só comida

A gente quer comida, diversão e arte

A gente não quer só comida

A gente quer saída para qualquer parte

A gente não quer só comida

A gente quer bebida, diversão, balé

A gente não quer só comida

A gente quer a vida como a vida quer

Compreende-se que, historicamente, o povo negro, que é a maioria de estudantes da EJA (LIMA, 2017), não apenas sofreu um processo de marginalização, mas um intenso processo de apagamento de sua história, com o objeto de quebra da identidade e autoestima, para evitar a emancipação social negra, podemos compreender que "ter o que comer" é o mínimo. Quando se não sabe quem é; muito dificilmente se saberá para onde se quer ir. De tal maneira, fazse um processo de dignidade negra o resgate de sua história.

Um ensino endurecido, influenciado pelo movimento tecnicista, que rega-se de numa técnica extrema que aliena, que insensibiliza e que desnorteia só reforça o projeto de robotização do ser; sem história e sem destino, diretamente afetados pelas políticas daqueles que detém o conhecimento e o poder. Poderíamos, até mesmo, entender o processo de "desassistir" as Artes na EJA, pelos governos, como um projeto de violação dos direitos das pessoas dentro de comunidade e favelas e boicote de suas cidadanias e emancipações.

\section{A Arte Que Identifica e Desenvolve Talentos}

É sabido, mesmo pelo senso comum, que grande parte dos gêneros musicais e de danças brasileiras são produtos da cultura periférica. O Rap, por exemplo, "[...] é a crônica do cotidiano da periferia" (SANTOS; MENDOZA; ELIAS); mecanismo pelo qual, geralmente jovens, se expressam e criam leituras críticas sobre suas realidades.

Independentes, cantores de Rap são críticos, considerados por estudiosos sociólogos natos capazes de criticar, refutar e tesar pensamentos e posicionamentos a cerca das estruturas sociais. Estes são graduados pelas ruas e as vivências apresentam-se enquanto docentes de seus cursos; a rima e a retórica as primeiras a serem estudadas. Pensando nisso, a EJA precisa estar preparada para absorção 
desses talentos, conversando segundo suas linguagens e desenvolvendo-os, visando o reconhecimento do ser crítico e transformador.

A visão de 'disciplina passatempo' já foi exposta neste artigo. Desta forma, não é necessária extensões a respeito do desinteresse apresentado por grande parte dos estudantes da EJA, em relação ao aprendizado em Artes, que a consideram 'fútil e fácil de passar'. O que se pretende discorrer, neste momento, é como burlar estas visões, garantindo o máximo de aproveitamento da turma e aprimoramento das relações acadêmicas.

Talentos - como no caso dos que fazem rap, que não são raros nesta modalidade de ensino, são coautores da identidade popular que se tem nos dias atuais. Embora, muito provavelmente, desconhecem este fato, eles são responsáveis pelo elo comunicativo que liga as classes marginalizadas pelo sistema, as quais pertencem, e o resto da sociedade. Uma vez instigados por uma metodologia, que se volte à valorização de suas realidades e opiniões, podem ser responsáveis por impulsionar a turma a uma nova perspectiva do que se é o ambiente escolar e a emancipação, proporcionando o nascer de uma escola, como defendida por Freire (1996), na qual seus alunos são autores da relação ensinoaprendizagem e prestigiados em suas características, qualidades e inteligências.

A arte, dentre as disciplinas, capaz de promover o autoconhecimento, a identificação, a sensibilidade, a emoção, a reflexão, criatividade, imaginação e etc., é a responsável pelo desenvolvimento das múltiplas inteligências. Tão quanto é o alicerce ao senso crítico e participação do aluno nas classes de qualquer matéria, visto que estimula a auto afetividade, concentração, interação, comunicação, expressão e etc. De tal modo, é possível vislumbrar que para o ideal funcionando da aprendizagem artística é fatidicamente relevante a adesão de um caráter atento identificador na EJA, o qual se escassa nos dias de hoje.

\section{Docente Transformado Transforma}

Muito embora discutissem a respeito do ensino artístico e estético, não podemos, de modo algum, esquecer-se de visualizar e tratar a cerca do ser o humano encarregado de ensiná-lo. No Brasil, a aprendizagem artística em EJA acontece em todos os seus eixos (equivalentes aos anos/séries), diferentemente da educação regular, na qual a instituição de ensino precisa optar por um dos três anos do ensino médio, para possuir Artes em sua grade curricular. Este é um ponto 
positivo e também uma vitória pra educação básica, visto que sua importância se alastra em todo processo formativo; entretanto, uma grande problemática aos educadores (as) da disciplina que não tem formação específica para tal.

Lidar com o desenvolvimento humano é, de longe, um enorme desafio e algo extremamente complexo. Pensar no desenvolver de um ser "já feito", ou seja, adulto, ou jovem é um desafio ainda maior. Os perfis são formados pessoas cansadas com o trabalho e com a rotina exaustiva, preocupadas com as contas, em situação de vulnerabilidade e/ou violências, situações de uso abusivo de drogas psicoativas e histórico de violações de direitos (LIMA, 2017). Apenas o retrato do stress no cotidiano periférico.

Atualmente, os cientistas já associam o desenvolvimento da depressão à exposição contínua a stress, devido ao seu impacto no hipocampo:

\begin{abstract}
A exposição a fatores estressantes tem papel importante no desenvolvimento de transtornos depressivos. Os mecanismos envolvidos nesta relação, no entanto, ainda são pouco conhecidos, mas algumas evidências sugerem a participação da formação hipocampal: 1. o estresse pode causar alterações plásticas no hipocampo, que incluem remodelação dendrítica e inibição de neurogênese. Drogas antidepressivas impendem estes efeitos, possivelmente por aumentarem a expressão de fatores neurotróficos; 2. a facilitação da neurotransmissão serotoninérgica no hipocampo atenua conseqüências comportamentais do estresse e produz efeitos antidepressivos em modelos animais; 3. o antagonismo do principal neurotransmissor excitatório no hipocampo, o glutamato, produz efeitos semelhantes; 4. o hipocampo parece estar "hiperativo" em animais mais sensíveis em modelos de depressão e em humanos resistentes à antidepressivos; 5. o hipocampo, em conjunto com o complexo amigdalar, parece ter papel fundamental na consolidação e evocação de memórias aversivas (JOCA; PADOVAN; GUIMALHÃES, 2003. [s.p.]).
\end{abstract}

Para além de fatores físicos, problemas sociais ou novidades são aceitos como estressadores e promotores de alterações comportamentais. Dentro das favelas, a população é alvo das mais diversas violências, sendo maioria em estatísticas de homicídio e suicídio (ATLAS, 2019); traços das políticas de marginalização e genocídio, as quais imergem as pessoas dessas comunidades em profundo stress.

É necessário um olhar compassivo, sensível, esperançoso e atento do educador aos comportamentos dentro da sala de aula, que sinalizem este adoecimento, uma vez que cabe ao professor traçar estratégias que permitam o aliviar da tensão produzida e o fluir da aprendizagem. Por isso, revolucionar o olhar do professor de Artes sobre si mesmo e sobre a importância de seu papel social é de imensurável relevância. 
A instabilidade advinda da falta de especializações em tantos gêneros (Música, Teatro, Dança e Arte Visual) alinhada a outros fatores já citados induz o olhar do educador a respeito de si, enquanto profissional, de limitação e despreparo que inicia um processo de fadiga e aceitação do desinteresse pela matéria, não permitindo visualizar as lacunas da autoestima e saúde mental desta modalidade.

Uma vez não visualizado, o professor transfere ao aluno total culpa a respeito da falta de produções ou interesses, perpetuando o perverso equívoco que fadam-os enquanto estudantes desinteressados. Quando, na verdade, seu empoderamento e atuação estão abalados.

Faz-se necessário lembrar que a(o) educador(a) para mediar o acesso aos saberes precisa ter acesso à produção do conhecimento e, para isso, uma atualização dos cursos superiores em Artes a esta demanda é imprescindível. Nesse sentido, a formação continuada é um desafio e possibilidade de superação do tecnicismo e do ensino sem historicidade e criticidade.

\section{Considerações}

Pensar a Educação de Jovens e Adultos na perspectiva do maior pensador, pedagogo e expoente dessa modalidade de ensino, Paulo Freire (1996), deve-se levar em consideração, sobretudo, o fortalecimento da autonomia, da identidade e construção da emancipação do educando, para que se reconheça enquanto sujeito histórico, ativo, crítico, autônomo e capaz de entender e intervir na sociedade, inclusive em direção da transformação social.

Rememorando a história da educação de jovens e adultos, percebe-se, que a EJA sempre foi encarada como uma educação compensatória e disciplinadora, cujo objetivo não era formar e qualificar as pessoas para a vida social, mas doutriná-las para atender as necessidades dos projetos ideológicos e econômicos das classes dominantes (LIMA, 2017).

A preocupação com a leitura e a escrita crítica e reflexiva, tendo como objetivo refletir e ampliar a visão de mundo e a vida dos sujeitos e da sociedade, é algo recente na EJA e uma bandeira cara, tendo em vista que o tempo todo os princípios e diretrizes da EJA sofre mudanças - tanto pedagógicas, como políticas -, pois trata-se de uma política educacional visada e executada a partir dos projetos ideopolíticos dos governos vigentes. A leitura não pode ser resumida à capacidade de soletrar e entender as letras, palavras, mas de compreender as mensagens, as ideias, os códigos discursivos. É nessa perspectiva que 
pensadores e cientistas da educação tem defendido a inserção da arte e cultura como instrumentos de construção do saber, de visão de mundo, de perspectivas.

$\mathrm{Na}$ atualidade, vivenciamos uma crise na educação pública, marcada pelo desmonte do sistema educacional brasileiro através dos cortes orçamentários e das reformas educacionais implementadas, que têm impactado no fechamento de escolas e na precarização das condições de educação (materiais de estudo, trabalho, estrutura e dentre outros).

Nesse sentido, defender a arte na EJA se trata de uma questão elementar e ética, tendo em vista que a arte educação forma e prepara os sujeitos para a vida, na medida em que oferta fundamentos e condições para se refletir, compreender, questionar e modificar a realidade. O campo da arte possibilita um repertório intelectual e sensitivo formador de sujeitos pensantes capazes de modificarem suas vidas e o curso da história social.

\section{Referências}

ALMEIDA, Tamíris. A Arte nas escolas deve ir além de desenhos e pinturas. 2018. Disponível em <https://www.futura.org.br/a-arte-na-escola-deve-ir-alem-dasaulas-de-pintura-e-desenho/>. Acesso em: 17 de abril de 2020.

ATLAS da violência 2019. Fórum Brasileiro de Segurança Pública. Brasília: Rio de Janeiro: São Paulo: Instituto de Pesquisa Econômica Aplicada; Fórum Brasileiro de Segurança Pública, 2019

BALDAN, Merilin; ARCE, Alessandra. A representação da Pedagogia Tradicional e da Escola Nova segundo a propaganda e a produção teórica dos personagens do movimento renovador brasileiro: Um estudo da coleção "Escola Nova Brasileira de José Scaramelli. São Paulo. 2009. Disponível em: <http://www.histedbr.fe.unicamp.br/acer_histedbr/seminario/seminario8/_files/p3zX2 YD.pdf>. Acesso em: 15 de abril de 2020.

BITTAR, Eduardo; ALMEIDA, Guilherme Assis. Curso de Filosofia do Direito. São Paulo, Ed. Atlas, 2015.

BRASIL. Lei de Diretrizes e Bases da Educação Nacional, LDB. 9394/1996. São Paulo: Saraiva, 1996

CAMPOS, Josué; TEIXEIRA, Érika; GOELZER, Marlene. Arte, infância e formação de professores. Disponível em <http://www2.seduc.mt.gov.br/-/arte-infancia-eformacao-de-professor-1>. Acesso em: 07 de abril de 2020.

CHAGAS DE LIMA, Viviane; GONÇALVES DE LIMA, Geraldo. Um estudo reflexivo sobre o ensino de Artes na EJA: Compreendendo sua importância cognitiva para os estudantes do Segundo Seguimento do Ensino Fundamental. Canoas, 2015. 
Disponível em: <file://C:/Users/Sinesio/Downloads/1900-Texto\%20do\%20artigo5988-1-10-20150708.pdf>. Acesso em 06 de Abril de 2020.

FACIO, Amanda; Marcelino, Aquilane. A arte na Educação de Jovens e Adultos. Paraná, $2017 . \quad$ Disponível em <https://educere.bruc.com.br/arquivo/pdf2017/24626_12682.pdf>. Acesso em 16 de abril de 2020.

FREIRE, Paulo. Pedagogia da Autonomia: saberes necessários à prática educativa. São Paulo: Paz e Terra, 1996.

FUSARI, Maria Felisminda de Rezende e; FERRAZ, Maria Heloisa Correa de Toledo. A arte na educação escolar. São Paulo: Cortez, 1999.

JOCA, S. R. L.; PADOVAN, C. M.; GUIMARÃES, F. S. Estresse, depressão e hipocampo. [s.I.]: Revista Brasileira de Psiquiatria, 2003.

LIMA, Viviane Chagas de; LIMA, Geraldo Gonçalves. Reflexões Acerca do Ensino de Artes Visuais na EJA do Segundo Seguimento do Ensino Fundamental. São Paulo: Portal Educação, 2015.

LIMA, Marise Esteves. Relações étnico-raciais na EJA: geração, classe e raça na educação escolar brasileira. Sinergia, São Paulo, v. 18, n. 1, p. 65-72, jan./jun. 2017. Disponível em <https://ojs.ifso.edu.br>. Acesso em 17 de abril de 2020.

OLIVEIRA, Naidi. Conhece-te a ti mesmo... e te tornarás mais forte: Uma experiência em construção das identidades através do Teatro, no Colégio Estadual Almirante Barroso. Bahia, 2016. Disponível em: $<$ https://www.udesc.br/arquivos/ceart/id_cpmenu/2914/NAIDI_LOPES_DE_OLIVEIR A_ARTIGO_CONHECE_TE_A_TI_MESMO_15311464334568_2914.pdf>. Acesso em: 18 de abril de 2020.

RICHTER, Ivone Mendes. A formação do professor de Artes Visuais em uma perspectiva internacional: implicações para o ensino de arte no Brasil. In: OLIVEIRA, Marilda Oliveira, HERNÁNDEZ, Fernando (orgs). A formação do professor e o ensino das Artes Visuais. Santa Maria, RS: UFSM, 2005.

ROUSSEAU, Jean-Jacques. Emílio: ou da educação. Tradução de Roberto Leal Ferreira. São Paulo: Martins Fontes, 1999.

SÃO PAULO (SP) Secretaria Municipal de Educação, Diretoria de Orientação Técnica: Caderno de orientações didáticas para a EJA. Língua Estrangeira Inglês, etapas complementar e final.São Paulo: SME/DOT 2010.

SANTOS, Aparecida; MENDOZA, Babette; ELIAS, José. O Rap reinterpretado na rima o dia a dia da comunidade. Belo Horizonte, 2003. Disponível em: $<$ http://www.portcom.intercom.org.br/pdfs/4044219258380298560938588529738913 5823.pdf $>$.Acesso em 17 de Abril de 2020.

TITÃS. "Comida". Letras. Disponível em: <https://www.letras.mus.br/titas/91453/>. Acesso em: 19 de abril de 2020. 
VIANA, Valdira. Arte-educação na EJA. Bahia, 2017. Disponível em: <http://osid.org.py/v1/wp-content/uploads/2017/12/ARTIGO-VALDIRA-REIMAOARTE-E-EDUCACAO.pdf>. Acesso em 05 de abril de 2020.

VIEIRA, Marcílio. As reformas educacionais e o ensino de Artes. Rio Grande do Norte, 2011. Disponível em: <file:///C:/Users/Sinesio/Downloads/1900Texto\%20do\%20artigo-5988-1-10-20150708.pdf>. Acesso em 15 de abril de 2020. 